\title{
EQUILIBRIUM ADSORPTION BEHAVIORS AND KINETIC CHARACTERISTICS OF OXYMATRINE ON A SPHERICAL CELLULOSE ADSORBENT
}

\author{
Yan Sun, ${ }^{\mathrm{a}, *}$ Chun-Xiang Lin, ${ }^{\mathrm{b}}$ Ming-Hua Liu, ${ }^{\mathrm{b}}$ and Yi-Fan Liu ${ }^{\mathrm{b}}$ \\ An investigation was conducted on the adsorption of oxymatrine (OMT) \\ on a spherical cellulose adsorbent embedded with wattle bark tannin. \\ The results showed that the adsorption of the OMT on the adsorbent was \\ solution $\mathrm{pH}$ dependent and the adsorption process followed the \\ Freundlich adsorption isotherm. The adsorption kinetics of the OMT on \\ the adsorbent could be well described by the pseudo-second-order rate \\ model. And, the adsorption capacity calculated by the pseudo-second- \\ order rate model was close to the experimental data. Desorption and \\ regeneration experiments showed that the OMT adsorbed on the \\ adsorbent could be easily recovered by $50 \%$ methanol solution.
}

Keywords: Absorption Behaviors; Kinetics; Oxymatrine; Spherical Cellulose Absorbent; Embedded

Contact information: a: Center for Reproductive Medicine, Fujian Maternity and Child Health Hospital of Fujian Medical University Teaching Hospital , Fuzhou, Fujian, 350001,China; b: College of Environment \& Resources, Fuzhou University, 350108, China;

* Corresponding author: sunyan62@163.com

\section{INTRODUCTION}

Oxymatrine (OMT) and matrine are two primary components of the dried root of Sophora flavescens, which is a widely used traditional Chinese herbal drug. These compounds possess strong biological activities and exhibit potentially useful pharmacological activities (Kinghorn et al. 1984), such as analgesic, antipyretic, anti-cancer, antiinflammatory, and anti-virus properties, and are used in acute conditions such as colpitis, $\mathrm{HBV}$, and other cases requiring anti-bacterial or anti-virus effects. Therefore it is important to develop efficient methods for the separation and determination of MT and OMT from Chinese herbs.

There have been a few reports on the separation of these two compounds, including pH-zone-refining counter-current chromatography (CCC) (Yang et al. 1998), high-performance liquid chromatography (HPLC) (Ma and Cao 2000), and thin-layer chromatography (TLC) (Li and Yang 1994). However, these methods lack quantitative precision, have relatively low efficiency, or take a rather long analysis time. For example, the separation capacity of classical HPLC is relatively low, limited by the column capacity, and the stationary phase may be affected by losses. Although CCC has been used to separate and purify a large amount of active components from traditional Chinese medicinal herbs and other natural products ( $\mathrm{Li}$ et al. 2002), too much harmful solvent has to be used with the method. TLC is an inexpensive method, but the operational processes are fussy and tedious. 
Compared with the other methods, adsorption-desorption is considered as an effective and economic method to separate and extract active constituents from Chinese traditional medicine. It has the advantages of lower generation of residues, easy adsorbate recovery, and the possibility to reuse adsorbent.

Cellulose is regarded as the most abundant and renewable biopolymer in nature, and is one of the promising raw materials available in terms of cost for the preparation of various functional materials (Zugenmaier, 2001; Saito and Isogai, 2005). It is nontoxic, biodegradable, and can be chemically modified to possess new functional groups with the aim of preparing new products having special properties. The applications of cellulose to use as an adsorbent have been well documented (Liu et al. 2002a,b; Lin et al. 2009). Therefore, much attention has been drawn to this biopolymer or its derivatives for sorption. Tannins, natural biomass containing multiple adjacent hydroxyl groups, can be used as an alternative, effective, and efficient adsorbent (Matsumura and Usuda 1998; Nakano et al. 2001; Sengil et al. 2009). However, tannin is a water-soluble compound, which restricts its practical application as an adsorbent. Therefore, great efforts have been made to overcome this disadvantage, mainly by immobilizing tannins onto various waterinsoluble matrices such as agarose (Nakajima and Sakaguchi, 1987), viscose rayon fiber (Sakaguchi and Nakajima 1987), cellulose (Chibata et al. 1986), and other matrices ( (Nakajima and Sakaguchi 1990).

The present study describes the adsorption-desorption of OMT by cellulose adsorbent embedded with tannin. There have been few reports however of the use of a natural macromolecule adsorbent for adsorption of OMT. In order to improve the surface area, permeability, and hydraulic performance of the cellulose adsorbent, a spherical shape of the adsorbent was developed to further increase the adsorption efficiency (Liu et al. 2001, 2002).

\section{EXPERIMENTAL}

\section{Materials}

Masson pine bleached sulfate pulp cellulose was obtained from Nanping Paper industry Co., LTD, Fujian, China. Oxymatrine (98\%) was purchased from Xi an Honson Biotechnology Co., Ltd. Other reagents were commercial products supplied by ShenHui Chemical Reagent LTD. Co. Deionised water was used throughout the work.

\section{Preparation of Spherical Cellulose Adsorbent \\ Preparation of viscose fibre}

20.0 g (dry basis) of Masson pine bleached sulfate pulp cellulose was immersed into $20.0 \%$ of $\mathrm{NaOH}$ solution at room temperature for $2 \mathrm{~h}$. The excess alkali liquor was removed under reduced pressure, and the resulting mixture was aged at room temperature for 3.0 days to get optimum viscosity, which could be easily spheroidized. The alkali cellulose was put into a $500 \mathrm{~mL}$ three-mouth flask, and then $9.1 \mathrm{~mL} \mathrm{CS}_{2}$ was added into the flask, after stirring for $15 \mathrm{~min}$ with mechanic agitation, $210 \mathrm{~mL} 6 \%$ of $\mathrm{NaOH}$ solution and $0.028 \mathrm{~g}$ of sodium oleate (as surfacant) were added. The mixture was stirred for 3.0h at room temperature, and then the viscose fibre was obtained. 


\section{Embedded spherical cellulose adsorbent}

$30 \mathrm{~g}$ of alkali cellulose and $0.3 \mathrm{~g}$ of imbedding agent wattle bark tannin and $2.0 \mathrm{~g}$ of $\mathrm{CaCO}_{3}$ were put into a three-mouth flask, then $120 \mathrm{~mL}$ of dispersed phase transformer oil was added after stirring for 10 minutes, and $30 \mathrm{~mL}$ of distilled water and $0.6 \mathrm{~g}$ of dispersant sodium oleate were added. The viscosity of the system was adjusted by gelatin, after dispersing uniformly under the stirring at 200 revolutions per min. The mixtures were slowly heated up to $60{ }^{\circ} \mathrm{C}$ and reacted for $1.5 \mathrm{~h}$. After the reaction, the mixtures were allowed to cool to ambient temperature and moved out; then the upper oil phase was recovered and the lower phase containing cellulose beads was filtered. Dark brown spherical cellulose adsorbent was obtained. The product was washed with water and identified as the tannin-embedded spherical cellulose adsorbent.

\section{Adsorption Experiment}

Batch adsorption experiments were carried out by shaking $0.2 \mathrm{~g}$ of cellulose adsorbent with $25 \mathrm{~mL}$ OMT solution at the desired concentration and $\mathrm{pH}$ (adjusted with 1 $\mathrm{mol} / \mathrm{L} \mathrm{NaOH}$ or $\mathrm{HCl}$ solutions) in a conical flask for $2 \mathrm{~h}$. After equilibrium, the flasks contents were filtered to separate the sorbents from the solution, and the filtrate was analyzed for sorbate concentration by High Performance Liquid Chromatography (HPLC, HITACHI L-2000) method with Ultimate $5 \mu \mathrm{m}$ XB-C18 $(4.6 \times 250 \mathrm{~mm})$ column and mobile phase of acetonitrile-dehydrated alcohol-ultrapure water (80:10:10) at a flow rate of $1.0 \mathrm{~mL} / \mathrm{min}$, and refractive index detector. The amount of OMT adsorbed by the cellulose adsorbents, $q_{e}(\mathrm{mg} / \mathrm{g})$, was obtained as follows,

$$
q_{e}=\left(C_{0}-C_{e}\right) \times V / W
$$

where $C_{0}$ and $C_{e}(\mathrm{mg} / \mathrm{L})$ are the initial and final concentrations of OMT, respectively, $V$ the volume of solution ( $\mathrm{L})$, and $W$ is the weight of cellulose adsorbent (g).

The used adsorbent after adsorption was washed twice with 50\% methanol followed by distilled water several times to remove adsorbed OMT. It was reused for further adsorption studies.

\section{RESULTS AND DISCUSSION}

\section{Effect of pH on the Adsorption of OMT}

In the adsorption process, the $\mathrm{pH}$ of the aqueous solution is a critical controlling parameter (Taty-Costodes et al. 2003). The $\mathrm{pH}$ value will determine the extent of ionization of OMT and the surface charge of the adsorbents, which will affect the interaction between the adsorbate and the adsorbent. The effect of the hydrogen ions concentrations on the adsorption of OMT on cellulose adsorbent was as shown in Fig. 1.

It can be seen that both the removal rate and adsorption capacity of OMT increased with increasing $\mathrm{pH}$ in the range of 1-6, and then decreased in the $\mathrm{pH}$ range of 6.0 to 10.0. These facts indicated that the adsorption of OMT onto cellulose adsorbent was highly pH-dependent, and strong acidity or alkaline nature of the solution was not beneficial to the adsorption. At very low $\mathrm{pH}(1.0)$, the surface of the sorbent was more 
protonated (due to more $\mathrm{H}^{+}$ions), and the OMT existed mainly as positive ions. Thus, the chelating interaction of OMT with phenolic hydroxyls of adsorbent was suppressed, and the adsorption capacity was relatively lower. When the solution $\mathrm{pH}$ was higher, the availability of -OH- group increased, making more phenolic hydroxyls of the adsorbent ionized, which significantly promoted the chelating interaction of OMT, resulting in the obvious increase of adsorption capacity. However, when the solution $\mathrm{pH}$ was higher than the $\mathrm{pK}_{\mathrm{a}}$ value (5.77) of the OMT (Gong et al. 2003), the OMT existed mainly as molecules in solution,

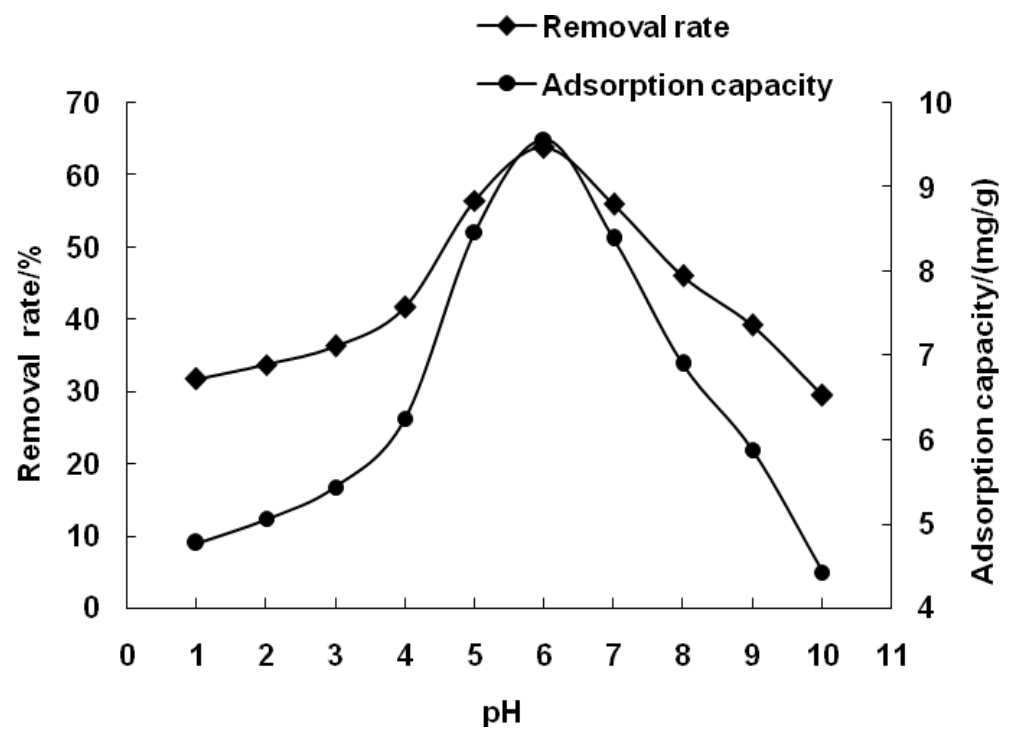

Fig. 1. Effect of $\mathrm{pH}$ on the adsorption. Sorption conditions: initial OMT concentration, $120 \mathrm{mg} / \mathrm{L}$; adsorption time, $2 \mathrm{~h}$; adsorbent usage, $0.2 \mathrm{~g} / 25 \mathrm{~mL}$; room temperature

\section{Adsorption Isotherm}

Adsorption isotherms are important for the description of how molecules or ions of adsorbate interact with adsorbent surface sites. They are also critical in optimizing the use of adsorbent. Hence, the correlation of equilibrium data using either theoretical or empirical equations is essential for the adsorption interpretation and prediction of the extent of adsorption. In this study, the analysis of the adsorption isotherms of OMT was carried out by applying the Langmuir and Freundlich equations (Saucedo et al. 1993).

The Langmuir isotherm describes monolayer adsorption and is based on the assumption that all the adsorption sites are energetically identical and adsorption takes place on a structurally homogeneous adsorbent (Ünlü and Ersoz 2006). The Langmuir isotherm is given by Eq. 1,

$$
\frac{C_{e}}{q_{e}}=\frac{1}{b \cdot Q_{0}}+\frac{C_{e}}{Q_{0}}
$$

where, the $C_{e}$ and $q_{e}$ are the concentration (mg/L) and amount (mg/g) of OMT adsorbed at equilibrium, respectively. The coefficient $b$ is a direct measure of the intensity of the adsorption process $(\mathrm{L} / \mathrm{mg})$, and $Q_{0}$ is a constant related to the area occupied by a 
monolayer of the adsorbent, reflecting the maximum adsorption capacity (mg/g). From a plot of $1 / q_{e}$ vs. $1 / C_{e}$, the values of $Q_{0}$ and $b$ can be obtained from its slope and intercept.

The Freundlich isotherm describes monomolecular layer coverage of adsorbent by the solutes (Al-Asheh et al 2000). It is an empirical isotherm model used for the adsorption on heterogeneous surfaces or surfaces supporting sites of varied affinities (Dabrowski 2001). The Freundlich isotherm model is formulated as,

$$
q_{e}=K C_{e}^{1 / n}
$$

or

$$
\lg q_{e}=\lg K+\frac{1}{n} \lg C_{e}
$$

where $K$ is a constant for the system relating to the bonding energy. The parameter $K$ can be defined as the adsorption or distribution coefficient, and it represents the quantity of the adsorbate adsorbed on the adsorbents for a unit equilibrium concentration. The slope $1 / n$ is a measure of the adsorption intensity.

Tables 1 and 2 show the results of Langmuir and Freundlich isotherm fits. Obviously, it could be observed that the data fit well to the classical Freundlich equation, rather than the Langmuir equation for the studied system, as reflected by the values of the coefficients of determination $\left(\mathrm{R}^{2}\right)$. Moreover, the calculated values of $Q_{0}$ in the Langmuir isotherm were higher than the actual value by a huge difference or reached negative values. The results meant that the adsorption isotherm of OMT onto cellulose adsorbent could not be described by Langmuir isotherm, implying an uneven distribution of the adsorption sites on the adsorbent surface, which is consistent with heterogeneous adsorption. This was because the cellulose adsorbents were constituted by the random combination of different monoflavonoid units corresponding to the structural heterogeneity of wattle bark tannins.

Table 1. Langmuir Parameters of Adsorption towards OMT

\begin{tabular}{cccc}
\hline Temperature $\left({ }^{\circ} \mathrm{C}\right)$ & $Q_{0}(\mathrm{mg} / \mathrm{g})$ & $b\left(\mathrm{~L} \cdot \mathrm{mg}^{-1}\right)$ & $\mathrm{R}^{2}$ \\
\hline 30 & -116.279 & -0.0482 & 0.5588 \\
40 & -161.29 & -0.033 & 0.2509 \\
50 & 76.336 & 0.0552 & 0.8361 \\
60 & 169.49 & 0.02592 & 0.6014 \\
\hline
\end{tabular}

Table 2. Freundlich Adsorption Isotherm of OMT

\begin{tabular}{ccccc}
\hline Temperature $\left({ }^{\circ} \mathrm{C}\right)$ & $K$ & $1 / n$ & $q_{\mathrm{e}}=\mathrm{KCe}$ & $\mathrm{R}^{2 / n}$ \\
\hline 30 & 0.1110 & 1.0581 & $q_{e}=0.111 \mathrm{Ce}^{1 / 1.0581}$ & 0.998 \\
40 & 0.06557 & 1.0348 & $q_{e}=0.06557 \mathrm{Ce}^{1 / 1.0348}$ & 0.996 \\
50 & 0.002584 & 0.9215 & $q_{e}=0.002584 \mathrm{Ce}^{1 / 0.9215}$ & 0.9973 \\
60 & 0.006835 & 0.9634 & $q_{e}=0.006835 \mathrm{Ce}^{1 / 0.9634}$ & 0.9989 \\
\hline
\end{tabular}




\section{Kinetic Study}

Figure 2 describes the adsorption kinetic curves. A high adsorption rate was observed at the beginning of adsorption, and then the adsorption rate slowed down as the adsorption equilibrium was approached.

To examine the underlying mechanism of the adsorption process, Lagergren pseudo first- (Eq. (9)) and second-order (Eq. (10)) kinetic models were applied (Rengaraj et al. 2004):

$$
\begin{aligned}
& \log \left(q_{e}-q_{t}\right)=\log q_{e}-k_{1} t \\
& \frac{t}{q_{t}}=\frac{1}{k_{2} q_{e}^{2}}+\frac{t}{q_{e}}
\end{aligned}
$$

where $q_{e}(\mathrm{mg} / \mathrm{g})$ and $q_{t}(\mathrm{mg} / \mathrm{g})$ are the adsorption capacity at equilibrium and time $t(\mathrm{~h})$, respectively, and $k_{1}\left(\mathrm{~min}^{-1}\right)$ and $k_{2}(\mathrm{mg} /(\mathrm{g} \cdot \mathrm{min}))$ are pseudo first and second order rate constants of adsorption, respectively. The pseudo first-order model is consistent with an assumption that the rate of occupation of the adsorption sites is proportional to the number of unoccupied sites. The value of $k_{1}$ can be calculated from the slope of the linear plot of $\log \left(q_{e}-q_{t}\right)$ versus $t$.

The pseudo second-order kinetic model is based on a chemical reaction mechanism (Iftikhar et al. 2009). It is assumed that the adsorption rate is controlled by chemical adsorption through sharing or exchange of electrons between the adsorbent and adsorbate. The value of $k_{2}$ can be calculated from the slope of the linear plot of $t / q t$ versus $t$ (Ozacara et al. 2008).

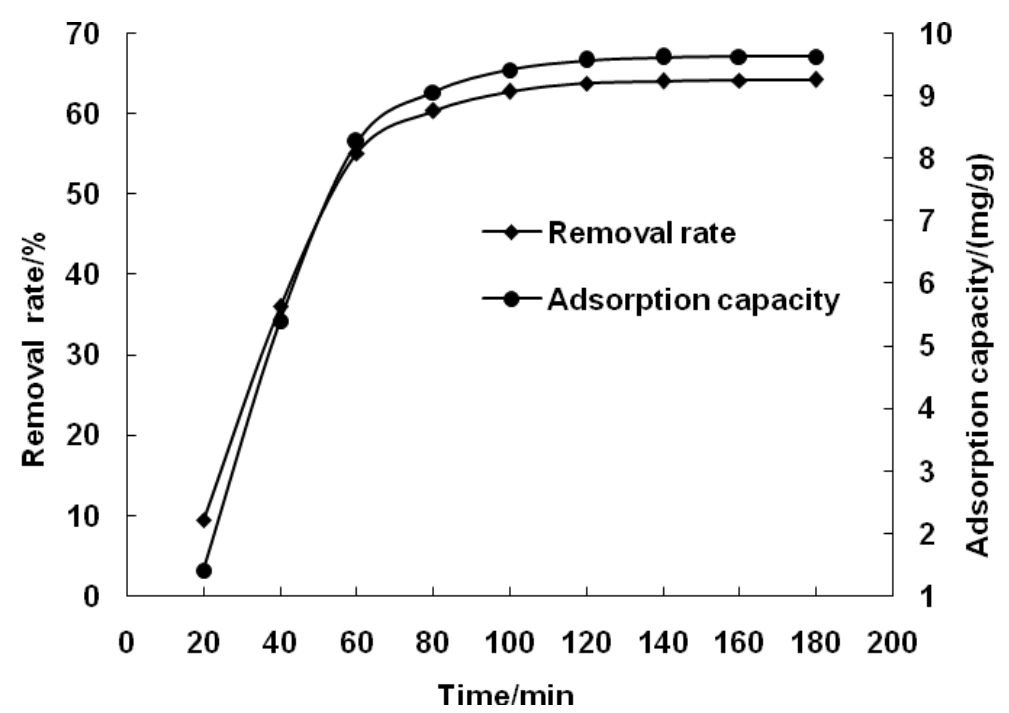

Fig. 2. Kinetics curve of the adsorption for OMT. Sorption conditions: $\mathrm{pH}$ value: 6 ; initial OMT concentration, $120 \mathrm{mg} / \mathrm{L}$; adsorbent usage, $0.2 \mathrm{~g} / 25 \mathrm{~mL}$; room temperature. 
The pseudo first- and second- order kinetic curves are shown in Figs. 3 and 4, and the coefficients of determination $\left(\mathrm{R}^{2}\right)$ as well as the calculated kinetic parameters are given in Table 3 . As shown in Table 3, although the correlation coefficient value of pseudo first-order kinetic curve was higher than 0.99, the experimental $q_{e}$ values did not agree with the calculated ones, obtained from the linear plots (Table 3). This showed that the adsorption of OMT onto cellulose adsorbent was not a first-order reaction. However, the linear plots of $t / q_{t}$ versus $t$ (Fig.4) showed a good agreement between experimental and calculated $q_{e}$ values (Table 3 ). The coefficients of determination for the second-order kinetic model were greater than 0.995, indicating the applicability of this kinetic equation and the second-order nature of the adsorption process of OMT on cellulose adsorbent.

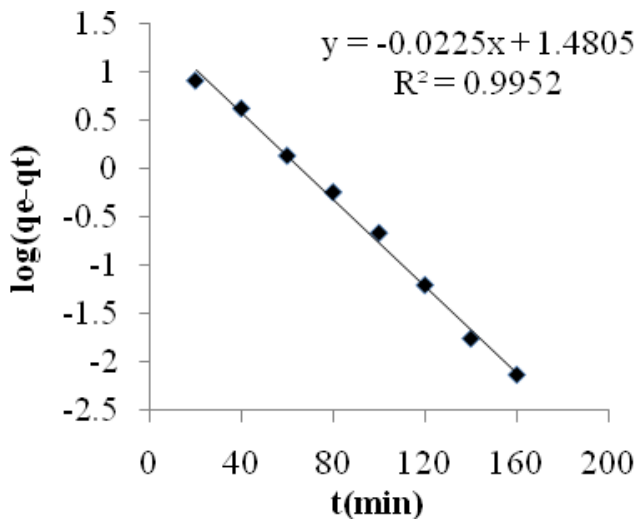

Fig. 3. Pseudo-first-order kinetic curves

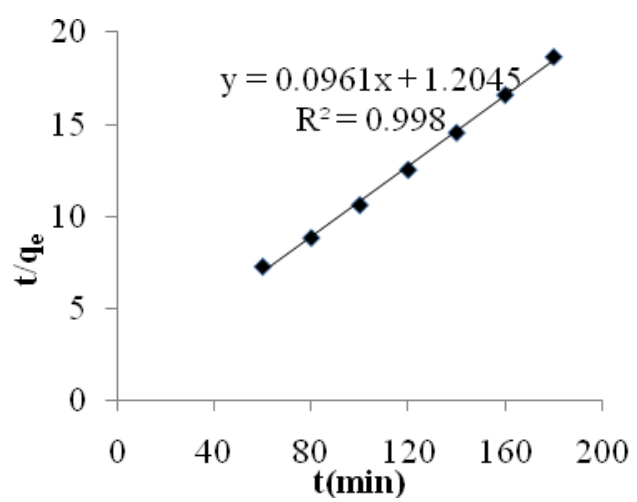

Fig. 4. Pseudo-second-order kinetic curves

Table 3. Dynamic Equations and Parameters

\begin{tabular}{|c|c|c|c|c|}
\hline \multirow{2}{*}{ Dynamic equations } & & \multicolumn{2}{|c|}{ Dynamic parameters } & \multirow{2}{*}{$\mathrm{R}^{2}$} \\
\hline & & $k_{i}$ & $q_{e}$ & \\
\hline $\begin{array}{l}\text { Pseudo-first-order } \\
\text { equation } \\
\log \left(q_{e}-q_{t}\right)=\log q_{e}-k_{1} t\end{array}$ & $y=-0.0225 x+1.4805$ & 0.0225 & 50.59 & 0.9952 \\
\hline $\begin{array}{l}\text { Pseudo-second-order } \\
\text { equation } \\
\text { t/q } q_{t}=1 /\left(k_{2} q_{e}{ }^{2}\right)+t / q_{e}\end{array}$ & $y=0.0961 x+1.2045$ & 0.007667 & 10.40 & 0.998 \\
\hline
\end{tabular}

\section{Desorption and Reproducibility}

In order to study the stability and reproducibility of the adsorbents, three cycles of adsorption/elution/regeneration were performed, using $50 \%$ of methanol as eluent. The results are listed in Table 4 . The results indicate that the adsorbents could be used many times without decreasing their adsorption capacities significantly. 
Table 4. Reproducibility of Cellulose Adsorbent

\begin{tabular}{lll}
\hline Repeated times & Adsorption capacity $(\mathrm{mg} / \mathrm{g})$ & Desorption efficiency $\%$ \\
\hline 0 & & \\
1 & 9.56 & 82.3 \\
2 & 8.24 & 80.2 \\
3 & 7.83 & 79.6 \\
\hline
\end{tabular}

Sorption conditions: $\mathrm{pH}$ value: 6 ; initial OMT concentration, $120 \mathrm{mg} / \mathrm{L}$; adsorption time, $2 \mathrm{~h}$; adsorbent usage, $0.2 \mathrm{~g} / 25 \mathrm{~mL} ; 50 \%$ methanol as eluent; desorption time, $60 \mathrm{~min}$; adsorption and desorption temperature, room temperature.

\section{CONCLUSIONS}

The adsorption ability of cellulose adsorbent embedded with wattle bark tannin was studied. The results showed that the static adsorption capacity of adsorbent towards the OMT could reach $9.56 \mathrm{mg} / \mathrm{g}$, and the adsorption process was found to be $\mathrm{pH}$ value dependent. Moreover, the adsorption processes followed the Freundlich adsorption isotherm and chemical adsorption was predominant in the adsorption process. The adsorbent could be regenerated by using $50 \%$ methanol as eluent, and the regeneration showed good reproducibility.

\section{ACKNOWLEDGMENT}

The research was financially supported by National Science Foundation of China (21077024) and Foundation of Fuzhou University (0460-022326).

\section{REFERENCES CITED}

Al-Asheh, S., Banat, F., Al-Omari, R., and Duvnjak, Z. (2000). "Prediction of binary sorption isotherms for the sorption of heavy metals by pine bark using single isotherm data," Chemosphere 41, 659-665.

Chibata, T. Tosa, Watanabe, T. Mori, Z., and Sakata, N. (1986). "Immobilized tannin-a novel adsorbent for protein and metal ion," Enzyme Microb. Technol. 8,130-136.

Dabrowski, A. (2001). “Adorption-from theory to practice,” Adv. Colloid Interf. Sci. 93, 135-224.

Gong, S. X, Su, X. D., Bo, T., Zhang, X., and Liu, H. W., and Li, K. A.(2003).

"Determination of dissociation constants of ten alkaloids by capillary zone electrophoresis,” J. Sep. Sci. 26, 549-554.

Iftikhar, A. R., Bhatti, H. N., Hanifa, M. A., and Nadeem, R. (2009). "Kinetic and thermodynamic aspects of $\mathrm{Cu}(\mathrm{II})$ and $\mathrm{Cr}(\mathrm{III})$ removal from aqueous solutions using rose waste biomass,” Journal of Hazardous Materials 161, 941-947.

Kinghorn, A. D., Balandrin, M. F. (1984). “Alkaloids,” Chem. Biol. Perspect.2, 105-148. 
Li, H. B., Lai, J. P., Jiang, Y., and Chen, F. (2002). "Preparative isolation and purification of salvianolic acid B from the Chinese medicinal plant Salvia miltiorrhiza by highspeed counter-current chromatography,” J. Chromatogr. A 943, 235-239.

Li, X. Y., and Yang, S. Q. (1994). "Determination of matrine in argent patch by TLC scanning method,” J. Chin. Med. 19, 671.

Lin, C. X., Zhan, H. Y., Liu, M. H., Fu, S. Y., and Lucia, L. A. (2009). "Novel preparation and characterization of cellulose microparticles functionalized in ionic liquids,” Langmuir 25, 10116-10120.

Liu, M.-H., Zhang, H., Deng, Y., Zhang, X-S., Liu, W.-G., and Zhan, H.-Y., 2001. "Removal and recovery of chromium(III) from aqueous solutions by spheroidal cellulose adsorbent," Water Environ. Res. 73, 322-328.

Liu, M. H., Deng, Y., Zhan, H. Y., and Zhang, X. S. (2002a). “Adsorption and desorption of copper(II) from solutions on a new spherical cellulose adsorbent,” Journal of Applied Polymer Science 84, 478-485.

Liu, M. H., and Zhang, X. S. (2002b). “Automatic on-line determination of trace chromium (VI) ion in chromium (III)-bearing samples by reverse adsorption process," Journal of the Society of Leather Technologists and Chemists 86, 1-5.

Ma, C. H., and Cao, T. H. (2000). "Determination of alkaloids in Sophora tonkinensis Gapnep. by HPLC,” Chin. J. Parametr. Anal. 20, 46-48.

Matsumura, T. and Usuda, S. (1989). "Applicability of insoluble tannin to treatment of waste containing americium,” J. Alloy Compd. 271-273, 244-247.

Nakajima, A., and Sakaguchi, T.(1987). "Recovery of uranium by tannins immobilized on agarose,” J. Chem. Tech. Biotechnol. 40, 223-232.

Nakajima, A., and Sakaguchi, T. (1990). "Recovery of uranium by tannin immobilized on matrices which have amino group," J. Chem. Technol. Biotechnol. 47, 31-38.

Nakano, Y., Takeshita, K., and Tsutsumi, T. (2001) “Adsorption mechanism of hexavalent chromium by redox within condensed tannin gel,” Water Res. 35,496-500.

Ozacara, M., Sengilb, I. A., and Turkmenler, H. (2008). "Equilibrium and kinetic data, and adsorption mechanism for adsorption of lead onto valonia tannin resin," Chemical Engineering Journal 143, 32-42.

Rengaraj, S., Kim, Y., Joo, C. K., and Yi, J. J. (2004). "Removal of copper from aqueous solution by aminated and protonated mesoporous aluminas: Kinetics and equilibrium,” Journal of Colloid and Interface Science 273, 14-21.

Saito, T., and Isogai, A. (2005). "Ion-exchange behavior of carboxylate groups in fibrous cellulose oxidized by the TEMPO-mediated system,” Carbohyd. Polym. 61,183-190.

Sakaguchi, T., and Nakajima, A. (1987). "Recovery of uranium from seawater by immobilized tannins,” Sep. Sci. Technol. 22,1609-1623.

Saucedo, I., Guibal, E., and Roussy, J. (1993). "Uranium sorption by glutamate glucan: A modified chitosan - part: Equilibrium studies,” Water SA 19, 113-118.

Sengil, I. A., Ozacar, M., and Turkmenler, H. (2009). "Kinetic and isotherm studies of Cu(II) biosorption onto valonia tannin resin,” J. Hazard. Mater. 162, 1046-1052.

Taty-Costodes, V. C., Fauduet, H., Porte, C., and Delacroix, A. (2003). "Removal of $\mathrm{Cd}(\mathrm{II})$ and $\mathrm{Pb}(\mathrm{II})$ ions, from aqueous solutions, by adsorption onto sawdust of Pinus sylvestris,” J. Hazard. Mater. B105, 121-142. 
Ünlü, N., and Ersoz, M.(2006). “Adsorption characteristics of heavy metal ions onto a low cost biopolymeric sorbent from aqueous solutions,” J. Hazard. Mater. B 136, 272-280.

Yang, F. Q., Quan, J., Zhang, T. Y., and Ito, Y. (1998). "Preparative separation of alkaloids from the root of Sophora flavescens Ait by $\mathrm{pH}$-zone-refining countercurrent chromatography,” J. Chromatogr. A 822, 316-320.

Zugenmaier, P. (2001). "Conformation and packing of various crystalline cellulose fibers,” Prog. Polym. Sci. 26, 1341-1417.

Article submitted: November 13, 2010; Peer review completed: December 26, 2010; Revised version received: January 5, 2011; Accepted: January 6, 2011; Published: January 10, 2011. 